\title{
Crystallographic account of an ultra-long period stacking ordered phase in an $\mathrm{Mg}_{88} \mathrm{Cos} \mathrm{Y}_{7}$ alloy
}

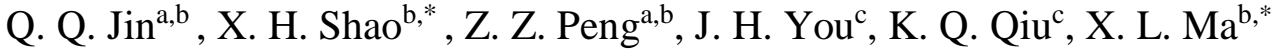 \\ ${ }^{a}$ School of Materials Science and Engineering, University of Science and Technology of China, \\ Hefei 230026, China \\ ${ }^{b}$ Shenyang National Laboratory for Materials Science, Institute of Metal Research, Chinese \\ Academy of Sciences, 72 Wenhua Road, 110016 Shenyang, China \\ ${ }^{c}$ School of Materials Science and Engineering, Shenyang University of Technology, 111 \\ Shenliao West Road, Economic \& Technological Development Zone, 110178 Shenyang, China \\ *Correspondence should be addressed to xhshao@imr.ac.cn or xlma@imr.ac.cn
}

\begin{abstract}
By atomic-scale high-angle annular dark field scanning transmission electron microscopy, we characterized a long period stacking ordered (LPSO) phase, $654 \mathrm{R}$, in an $\mathrm{Mg}_{88} \mathrm{Co}_{5} \mathrm{Y}_{7}$ (at.\%) as-cast alloy, which is an ordered intergrowth of $15 \mathrm{R}$ and $12 \mathrm{H}$ LPSO phase. The unique stacking sequence of $654 \mathrm{R}$ LPSO phase can be described as $\left[(\mathrm{T} 2)_{10}(\mathrm{~T} 3 \overline{\mathrm{T}} 3)_{14}\right]_{3}$, with lattice parameters of $a=$ $0.321 \mathrm{~nm}, c=170.4 \mathrm{~nm}$, and a space group of $R \overline{3} m$. T/ $\overline{\mathrm{T}}$ refers to $\mathrm{AB}^{\prime} \mathrm{C} / \mathrm{AC}^{\prime} \mathrm{B}$ building block, while normal and subscript number respectively represent the number of $\mathrm{Mg}$ layers sandwiched between $\mathrm{T} / \overline{\mathrm{T}}$ and the number of sub unit cells. The formation mechanism of 654R LPSO phase is also proposed.
\end{abstract}

Keywords: Magnesium alloys; Long period stacking ordered (LPSO) structure; HAADF-STEM; building block 
Magnesium alloys attract considerable attention owing to their low density and high specific strength $[1,2]$. In recent decades, Mg-M-RE $(\mathrm{M}=\mathrm{Al}, \mathrm{Co}, \mathrm{Ni}, \mathrm{Cu}$ and $\mathrm{Zn}$; $\mathrm{RE}=$ rare earth: $\mathrm{Y}, \mathrm{Gd}, \mathrm{Tb}$, Dy, Ho, Er, and Tm) alloys [3-12] containing long period stacking ordered (LPSO) structures have been a research focus due to their superior mechanism properties [6-8] and unique structure characteristics [10-15]. Most of $\mathrm{Mg}_{97} \mathrm{M}_{1} \mathrm{RE}_{2}(\mathrm{M}=\mathrm{Zn}, \mathrm{Ni}, \mathrm{Cu})$ as-cast alloys containing LPSO structures possess tensile yield strength higher than $297 \mathrm{MPa}$ after traditional hot-extrusion process [6-8], which is better than the conventional Mg alloys [8].

Understanding the microstructure features [10-15] and formation mechanisms $[7,13,16,17]$ of LPSO phases is a crucial issue if we are to properly tailor LPSO structures to achieve a desired property of Mg alloys. Great efforts thus have been devoted to exploring new polytypes of LPSO phases in new Mg-M-RE systems [10, 12, 13, 15, 18-22], studying the atomic stacking features of LPSO structures [18-21], and uncovering the in-plane ordered character of LPSO phases in various $\mathrm{Mg}$ alloys [10, 12, 13, 15, 22]. Among the LPSO structures, 10H, 18R, 14H and 24R LPSO structures containing $\mathrm{AB}^{\prime} \mathrm{C}^{\prime} \mathrm{A}$ building blocks were observed in some $\mathrm{Mg}-\mathrm{M}-\mathrm{RE}(\mathrm{M}=\mathrm{Al}, \mathrm{Co}, \mathrm{Ni}, \mathrm{Cu}$ and $\mathrm{Zn})$ systems $[5,6,8,10,11,18]$, while $15 \mathrm{R}, 12 \mathrm{H}$ and $21 \mathrm{R}$ LPSO structures featuring $\mathrm{AB}^{\prime} \mathrm{C}$ building blocks were only reported in Mg-Co-Y alloys [11, 21]. Recently, we unraveled that the co-existence of $\mathrm{AB}^{\prime} \mathrm{C}^{\prime} \mathrm{A}$ and $\mathrm{AB}^{\prime} \mathrm{C}$ building block in a single LPSO structure in an $\mathrm{Mg}_{92} \mathrm{Co}_{2} \mathrm{Y}_{6}($ at.\%) as-cast alloy [21]. Moreover, the formation of LPSO structures was reported to depend on the chemical composition and fabrication history of Mg alloys. LPSO structures precipitated from the amorphous region enriched with solute atoms for the rapid solidification $\mathrm{Mg}-\mathrm{Zn}-\mathrm{Y}$ alloys fabricated during annealing [23]; 14H LPSO structures could transform from solid solution in some Mg-Zn-Gd alloys after heat-treatment [16]; while 18R LPSO structures could form directly from the melt [17]. However, seldom evidence has been given to explain the detailed formation mechanism of LPSO structures.

In present work, we characterized microstructural feature of 654R LPSO phase, ordered intergrowth of $15 \mathrm{R}$ and $12 \mathrm{H}$, in an $\mathrm{Mg}_{88} \mathrm{Co}_{5} \mathrm{Y}_{7}$ (at.\%) as-cast alloy by the transmission electron microscopy (TEM) and atomic resolution high-angle annular dark field scanning transmission electron microscopy (HAADF-STEM). The stacking sequance of 654R LPSO phase is $\left[(\mathrm{T} 2)_{10}(\mathrm{~T} 3 \overline{\mathrm{T}} 3)_{14}\right]_{3}$ by the introduced description [21]. The lattice parameter of $654 \mathrm{R}$ is derived as $a=0.321 \mathrm{~nm}$ and $c=170.4 \mathrm{~nm}$, with a space group of $R \overline{3} m$. We further proposed the formation 
mechanism of this LPSO structure based on the atomic experimental results.

An ingot of Mg-Co-Y ternary alloy with a nominal composition Mg-5.0 at.\% Co-7.0 at.\% Y was prepared in a high frequency induction melting furnace [19]. Thin foils for TEM and STEM observations were cut from the as-cast ingots, mechanically grinded, polished and ion-milled in a Gatan PIPS 691. Two-beam bright field (BF) imaging techniques were carried out on a Tecnai $\mathrm{G}^{2}$ F30 TEM operated at $300 \mathrm{kV}$. The HAADF-STEM studies were performed with an aberration corrected $\operatorname{Titan}^{3 \mathrm{TM}} \mathrm{G}^{2} 60-300$, operated at $300 \mathrm{kV}$. We here introduce a new notation to characterize the ultra-long LPSO phase, for example, $(\mathrm{T} n)_{\mathrm{m}}$, which can be described as follow: $\mathrm{AB}^{\prime} \mathrm{C}$ (and/or $\mathrm{AC}^{\prime} \mathrm{B}$ ) building block are defined as T-block and denoted as $\mathrm{T}$ (and/or $\overline{\mathrm{T}}$ ), where the bar sign presents the opposite shear direction of the block. The $n(n=$ integer $)$ means the number of $\mathrm{Mg}$ layers sandwiched between $\mathrm{T}$ or $\overline{\mathrm{T}}$, written as $n-\mathrm{Mg}$; the subscript number $\mathrm{m}$ refers to the number of sub unit cells with same size and symmetry [21].

A new type of LPSO structure in an $\mathrm{Mg}_{88} \mathrm{Co}_{5} \mathrm{Y}_{7}$ as-cast alloy was detected by TEM imaging under a two-beam diffraction condition, a few degrees off $[2 \overline{1} \overline{1} 0]_{\alpha}$ zone axis, as shown in Fig. 1a. The microstructure of this LPSO is not uniform and contains left area of relatively perfect stacking sequence and right area with a variety of faulted stacking sequence. In order to study the microstructural feature of this new type of LPSO phase, we denoted 16 regions with either same size or similar structural character by rectangles (Fig. 1a).

Fig. 1b shows the low-magnification HAADF-STEM image of the alternate arrays of thin and thick laths in Region 2-8, recorded alone $[U V .0]_{\alpha}$ zone axis to obtain better contrast. One can see that 10 and 28 vertical bright lines were detected in thin and thick laths, respectively. A local region, as indicated by the rectangular frame in Fig. 1b, is enlarged and shown in Fig 1c. The atomic stacking sequence and chemical composition contrast reveals that these building blocks all have $\mathrm{AB}^{\prime} \mathrm{C}$ stacking sequence. Inspection of these building blocks uncovers that these building blocks make up $15 \mathrm{R}$ and $12 \mathrm{H}$ structures [11], e.g., T2 and T3 $\overline{\mathrm{T}} 3$. Correspondingly, one structural unit containing a pair of thin lath and thick lath can be expressed as (T2) ${ }_{10}(\mathrm{~T} 3 \overline{\mathrm{T}} 3)_{14}$ by the newly introduced symbol, with 218 atomic layers. Meanwhile, the stacking sequence of whole LPSO phase can be described as $\left(\underline{\mathrm{AB}^{\prime} \mathrm{CBCBC}} \underline{\mathrm{C}^{\prime} \mathrm{ACACA}} \underline{\mathrm{B}^{\prime} \mathrm{AB}}\right)_{3} \underline{\mathrm{AB}^{\prime} \mathrm{CBC}}\left(\underline{\mathrm{BC}^{\prime} \mathrm{ACACAC}} \underline{\mathrm{C}^{\prime} \mathrm{BBA}}\right)_{14}(\mathbf{B} \ldots)$, where the underlined units represent building block of $\mathrm{T}$ or $\overline{\mathrm{T}}$. If we assume the atoms in the $1^{\text {st }}$ atomic layer are at atomic positions of $\mathrm{A}$, the atoms in the $219^{\text {th }}, 437^{\text {th }}$, and $655^{\text {th }}$ layers are at atomic positions of $\mathrm{B}, \mathrm{C}$ and $\mathrm{A}$ 
again, respectively. Thus, the new LPSO phase observed here can be determined as 654R LPSO structure and expressed as $\left[(\mathrm{T} 2)_{10}(\mathrm{~T} 3 \overline{\mathrm{T}} 3)_{14}\right]_{3}$. The lattice parameters of $654 \mathrm{R}$ structure are $a=0.321$ $\mathrm{nm}$ and $c=170.4 \mathrm{~nm}$, derived by assuming $a_{654 \mathrm{R}}=a_{\mathrm{Mg}}$ and $c_{654 \mathrm{R}}=\frac{1}{2} \times 654 \times c_{\mathrm{Mg}}$. It is worthwhile to mention that inversion centers $\overline{1}$ exist at the center of T-blocks stressed in bold if the LPSO phase is expressed as $(\mathrm{T} 2)_{5} \mathbf{T}(2 \mathrm{~T})_{5}(3 \overline{\mathrm{T}} 3 \mathrm{~T})_{6} 3 \overline{\mathrm{T}} 3 \mathbf{T} 3 \overline{\mathrm{T}} 3(\mathrm{~T} 3 \overline{\mathrm{T}} 3)_{6}$, pointed out by arrows in Fig. 1c, suggesting that the space group should be $R \overline{3} m$ [21]. Fig. 1d presents the corresponding fast Fourier transform (FFT) pattern of image in Fig. 1b. The extra spots at positions of $n / 109(0001)_{\mathrm{Mg}}(n$ is an integer) in the pattern can be indexed as $(0003 n)_{654 \mathrm{R}}$, which confirms the 654R LPSO structure. Note that the sharp contrast of diffraction pattern rather than diffusion streaks indicates that 654R LPSO structure is highly ordered along the stacking direction.

Fig. 2a-d provide the microstructural characters of the disordered structures in Regions 9-15 in Fig. 1a. Viewed at low magnification along the $[U V .0]_{\alpha}$ zone axis, the stacking faulted structures exhibit various contrast in Fig. 2a. These stacking faulted structures were further studied by atomic-resolution HAADF-STEM imaging, demonstrating they are (T2) 3 , T1 $\overline{\mathrm{T}} 2, \mathrm{~T} 20$ and T8/T 8 blocks, respectively. Interestingly, the (T2) ${ }_{10},(\mathrm{~T} 2)_{3}$ and $\mathrm{T} 1 \overline{\mathrm{T}} 2$ blocks always exist at the beginning of each marked region, while the T20 and T/T 8 blocks appear in the midst of T3T $3(12 \mathrm{H})$ structures. Fig. $2 \mathrm{~b}$ is an HAADF-STEM image of the beginning of Region 15, showing the transformation between (T2) $)_{3}$ and $\mathrm{T} 1 \overline{\mathrm{T}} 2 \overline{\mathrm{T}} 3$ from top to bottom. According to the atomic experimental results, the transformation process can be realized by two steps and expressed as: (T2) $)_{3} \rightarrow$ T1T3T2 $\rightarrow$ $\mathrm{T} 1 \overline{\mathrm{T}} 2 \overline{\mathrm{T}} 3$. To analyze the transformation mechanism, their stacking sequences are listed as follow:

$\mathrm{AB}^{\prime} \mathrm{CBCB} \underline{\mathrm{C}^{\prime} \mathrm{ACACA}{ }^{\prime} \mathrm{BAB} \ldots} \quad(\mathrm{T} 2)_{3}$

$\mathrm{AB}^{\prime} \mathrm{CBCB}^{\prime} \underline{\mathrm{ABABAB}} \mathbf{B}^{\prime} \mathrm{CBC} \ldots \quad \mathrm{T} 1 \overline{\mathrm{T}} 3 \mathrm{~T} 2 \quad$ (2)

$\mathrm{AB}^{\prime} \mathrm{CBCB}{ }^{\prime} \mathrm{ABABA}$ CACA... $\quad$ T1 $1 \overline{\mathrm{T}} 2 \overline{\mathrm{T}} 3 \quad$ (3)

It is apparent that the motion of Shockley partial dislocations with a Burgers vector of $\frac{\mathbf{a}}{3}<10 \overline{1} 0>_{\alpha}$, marked by " $\mathrm{T}$ ” in Fig. 2b, plays a key role in transformation from (T2) $)_{3}$ to $\mathrm{T} 1 \overline{\mathrm{T}} 2 \overline{\mathrm{T}} 3$ structures. The $(\mathrm{T} 2)_{3}$ and $\mathrm{T} 1 \overline{\mathrm{T}} 2 \overline{\mathrm{T}} 3$ structures are not unique instances. (T2) 3 also located at the beginning of Region 9 and 12, and the T1 $1 \overline{\mathrm{T}} 2 \overline{\mathrm{T}} 3$ structure formed at the beginning of Region 16.

Fig. 2c shows the stacking sequence of $\overline{\mathrm{T}} 8$ in $12 \mathrm{H}$ structure in Region 13 . The intensity profile of the interested region demonstrates eight atomic layers enriched with $\mathrm{Co} / \mathrm{Y}$ elements in comparison 
with three Mg layers in $12 \mathrm{H}$ structure. In analogous, Fig. 2d presents T20 building block of 20 atomic layers enriched with $\mathrm{Co} / \mathrm{Y}$, indicated by the intensity profile of the region inserted in Fig. $2 \mathrm{~d}$. These 8 or 20 atomic layers with $\mathrm{ABAB}$ stacking sequence should be the supersaturated $\mathrm{Mg}$ solid solution enriched with $\mathrm{Co} / \mathrm{Y}$. This $\mathrm{Mg}$ solid solution could transform into metastable $\beta^{\prime \prime}$ structure [24], indicating the supersaturated $\mathrm{Mg}$ is unstable. In addition, another faulted structure among $12 \mathrm{H}$ structure, $\overline{\mathrm{T}} 4 \overline{\mathrm{T}} 2$, exist in Region 1, as is displayed in Fig. 2e.

All the stacking features of 654R LPSO structure in Regions 1-16 were investigated by atomic resolution HAADF-STEM imaging and expressed by newly introduced symbols, listed in Table 1. The stacking sequence of structure in Regions 2-8, 10 and 11 can be expressed as (T2) $)_{10}(\mathrm{~T} 3 \overline{\mathrm{T}} 3)_{14}$, consisting of 218 atomic layers. By contrast, the structure in Regions 1, 9, 12 and 13 beginning with $(\mathrm{T} 2)_{3}$ or $\mathrm{T} 1 \overline{\mathrm{T}} 2 \overline{\mathrm{T}} 3$ structures are also comprised of 218 atomic layers, which contains $\mathrm{T} 20$ or $\overline{\mathrm{T}} 8 / \mathrm{T} 8$ faulted structures in the midst of the regions. Comparing the expression of the local stacking sequences in region 9, 13 and 15 listed in table 1, there is a possible transformation between T20 and Т3Т $8 \overline{\mathrm{T}} 3$ structures under proper thermal condition, which could lead to growth or degeneration of $(\overline{\mathrm{T}} 3 \mathrm{~T} 3)_{\mathrm{n}}$ structures. However, $\overline{\mathrm{T}} 8(\overline{\mathrm{T}} 3 \mathrm{~T} 3)_{\mathrm{n}}$ structure could not transform into $\overline{\mathrm{T}} 2 \overline{\mathrm{T}} 3(\overline{\mathrm{T}} 3 \mathrm{~T} 3)_{\mathrm{n}}$ or $\overline{\mathrm{T}} 3 \mathrm{~T} 2$ (T3T3) structure. This is due to the inherent relationship between $\mathrm{T} / \overline{\mathrm{T}}$ building blocks and the sandwiched $\mathrm{Mg}$ layers between them. In detail, $\mathrm{T}$ and $\mathrm{T}(\overline{\mathrm{T}}$ and $\overline{\mathrm{T}})$ building blocks usually separated by $\mathrm{Mg}$ layers of even number, while the $\mathrm{T}$ and $\overline{\mathrm{T}}$ blocks separated by $\mathrm{Mg}$ layers of odd number in Mg-M-RE alloys. Fig. 3 illustrates a histogram of the arrangement of T2 and (T3T 3 ) structures and the number of layers in various structures of each region, implying that the perfect structure mainly depends on (T2) 10 building blocks. It is noteworthy that either T20 or $\bar{T} / \mathrm{T} 8$ faulted structures exist in the midst of $12 \mathrm{H}$ structure in the regions beginning with $(\mathrm{T} 2)_{3}$ or $\mathrm{T} 1 \overline{\mathrm{T}} 2 \overline{\mathrm{T}} 3$ structures.

Regarding the coexistence of $12 \mathrm{H}$ and $15 \mathrm{R}$ with a coherent orientation relationship in $654 \mathrm{R}$, in what follows we discuss the possible formation mechanism of this unique LPSO structures. On the one hand, coherent lamellar $15 \mathrm{R}$ and $12 \mathrm{H}$ may indicate that transformation process should be a solid-state transformation. That is, L (liquid) $\rightarrow \mathrm{Mg}$ solid solution $\rightarrow 15 \mathrm{R}+12 \mathrm{H}$, instead of $\mathrm{L} \rightarrow$ $15 \mathrm{R}+12 \mathrm{H}$. Combining that LPSO structures precipitated from amorphous phase or solid solutions $[16,23]$, there's a strong possibility that LPSO structures in Mg alloys could be formed via a solid transformation. On the other hand, 15R (T2 structures) may be the leading phase and $12 \mathrm{H}$ (T3 $\overline{\mathrm{T}} 3$ structures) locates between $15 \mathrm{R}$, considering all of the untransformed supersaturated laths of $\mathrm{Mg}$ 
solid solution ( $\overline{\mathrm{T}} 8$ and T20 in Figs. 2 and 3) locates in 12H. It further suggests that the transformation of $15 \mathrm{R}$ and $12 \mathrm{H}$ from the solid solution may be a eutectoid reaction. This is analogous to cooperative growth of ferrite and cementite where the two phases behave as equal partners in pearlite [25]. It was documented that the lamellar spacing and the thickness of ferrite and cementite in pearlite depend on the undercooling, the composition and temperature fluctuation [25]. Similarly, all these factors possibly affect the distance between $15 \mathrm{R}$ laths and thickness of $15 \mathrm{R}$ and $12 \mathrm{H}$.

Correspondingly, Fig. 4 illustrates the formation process of $654 \mathrm{R}$ based on the above analysis. First, supersaturated Mg solid solution was transformed from the liquid. Second, 15R (T2 structure) as the leading phase nucleates periodically depending on the undercooling. In our case, the spacing of laths is 218 atomic layers. Third, these leading T2 structures then grew laterally into either (T2) 10 or (T2) 3 structures along c-axis. Forth, $12 \mathrm{H}$ (T3T3 3 structure) nucleates on both sides (left and right) of $(\mathrm{T} 2)_{10}$ or $(\mathrm{T} 2)_{3}$ structures. Thus, the two units of $\mathrm{T} 3 \overline{\mathrm{T}} 3$ building blocks in between the (T2) 10 or $(\mathrm{T} 2)_{3}$ structures expanded sideways in opposite directions along c-axis, as shown by a pair of arrows in step 4. Finally, in the regions beginning with (T2) 10 structures, either perfect $12 \mathrm{H}$ structures or the intergrowth of $12 \mathrm{H}$ and $\overline{\mathrm{T}} 4 \overline{\mathrm{T}} 2$ stacking fault structure would be produced when the two (T3 $\overline{\mathrm{T}} 3)_{\mathrm{n}}$ structures met in the midst of $12 \mathrm{H}$. And stacking faulted structures may be left in other regions.

In summary, based on Cs-corrected HAADF-STEM observations at the atomic level, the crystallography and formation mechanism of $654 \mathrm{R}$ in the $\mathrm{Mg}_{88} \mathrm{Co}_{5} \mathrm{Y}_{7}$ (at.\%) as-cast alloy has been discussed. It is an ordered intergrowth of $15 \mathrm{R}$ and $12 \mathrm{H}$ LPSO structure. The unit cells and space group of the new LPSO structure are formulated as: 654R, [(T2) $\left.{ }_{10}(\mathrm{~T} 3 \overline{\mathrm{T}} 3)_{14}\right]_{3}, R \overline{3} m$. Its lattice parameter can be derived as: $a=0.321 \mathrm{~nm}$ and $c=170.4 \mathrm{~nm}$. The $654 \mathrm{R}$ LPSO structure is proposed to be transformed from supersaturated $\mathrm{Mg}$ solid solution via eutectoid transformation, which is based on the remained $\mathrm{ABAB}$ stacking sequence enriched with $\mathrm{Co} / \mathrm{Y}$ atoms in the midst of $12 \mathrm{H}$ structures.

\section{Acknowledgements}

This work is supported by the National Science Foundation of China (Grant No. 51301177), the Innovation Fund of IMR (SCJJ-2013-PY-08 \& 2015-PY08) and the Youth Fund of SYNL fund (2015FP18). The authors are grateful to Prof. S. J. Zheng and Dr. X. B. Hu for fruitful discussion. 


\section{References}

[1] L.L. Rokhlin, Magnesium alloys containing rare earth metals: structure and properties, Crc Press, 2003.

[2] I. Polmear, Light Alloys, fourth ed., Elsevier, Oxford, 2006.

[3] Y. Kawamura, K. Hayashi, A. Inoue, T. Masumoto, Mater. Trans. 42 (2001) 1171.

[4] X.H. Shao, Z.Q. Yang, X.L. Ma, Acta Mater. 58 (2010) 4760.

[5] M. Matsuda, S. Ii, Y. Kawamura, Y. Ikuhara, M. Nishida, Mat. Sci. Eng. A 393 (2005) 269.

[6] Y. Kawamura, T. Kasahara, S. Izumi, M. Yamasaki, Scripta Mater. 55 (2006) 453.

[7] Y. Kawamura, M. Yamasaki, Mater. Trans. 48 (2007) 2986.

[8] T. Itoi, K. Takahashi, H. Moriyama, M. Hirohashi, Scripta Mater. 59 (2008) 1155.

[9] E. Abe, A. Ono, T. Itoi, M. Yamasaki, Y. Kawamura, Phil. Mag. Lett. 91 (2011) 690.

[10] H. Yokobayashi, K. Kishida, H. Inui, M. Yamasaki, Y. Kawamura, Acta Mater. 59 (2011) 7287.

[11] S.-B. Mi, Q.-Q. Jin, Scripta Mater. 68 (2013) 635.

[12] M. Yamasaki, M. Matsushita, K. Hagihara, H. Izuno, E. Abe, Y. Kawamura, Scripta Mater. 78-79 (2014) 13.

[13] K. Kishida, H. Yokobayashi, H. Inui, Phil. Mag. 93 (2013) 2826.

[14] S.Y. Ma, L.M. Liu, S.Q. Wang, Mater. Sci. Forum. 749 (2013) 569.

[15] K. Kishida, K. Nagai, A. Matsumoto, A. Yasuhara, H. Inui, Acta Mater. 99 (2015) 228.

[16] M. Yamasaki, M. Sasaki, M. Nishijima, K. Hiraga, Y. Kawamura, Acta Mater. 55 (2007) 6798.

[17] Y.M. Zhu, A.J. Morton, J.F. Nie, Acta Mater. 60 (2012) 6562.

[18] Q.-Q. Jin, C.-F. Fang, S.-B. Mi, J. Alloy. Compd. 568 (2013) 21.

[19] Q.-Q. Jin, S.-B. Mi, J. Alloy. Compd. 582 (2014) 130.

[20] J.E. Saal, C. Wolverton, Acta Mater. 68 (2014) 325.

[21] Q. Q. Jin, X.H. Shao, X. B. Hu, Z. Z. Peng, X. L. Ma, (to be published).

[22] K. Kishida, H. Yokobayashi, H. Inui, M. Yamasaki, Y. Kawamura, Intermetallics. 31 (2012) 55.

[23] M. Nishida, Y. Kawamura, T. Yamamuro, Mat. Sci. Eng. A 375-377 (2004) 1217.

[24] M. Nishijima, K. Yubuta, K. Hiraga, Mater. Trans. 48 (2007) 84.

[25] A. Borgenstam, P. Hedström, M. Hillert, P. Kolmskog, A. Stormvinter, J. Ågren, Metall. Mater. Trans. A 42 (2011) 1558. 


\section{Figure Captions}

Fig. 1 (a) A low magnification bright field TEM image recorded with electron beams a few degree off $[2 \overline{1} \overline{1} 0]_{\alpha}$ zone axis, showing ordered thin laths and thick laths alternated in the LPSO phase in $\mathrm{Mg}_{88} \mathrm{Co}_{5} \mathrm{Y}_{7}$ (at. \%) as-cast alloy. (b) A low magnification HAADF-STEM image of the LPSO structure in left part of (a) obtained along $[U V .0]_{\alpha}$ zone axis. 10 and 28 vertical bright lines were detected in thin laths and thick laths, respectively. (c) An atomic resolution HAADF-STEM image demonstrates the stacking and chemical ordered structure in the interested region, framed by the rectangle $\mathrm{c}$ in (b), indicating the thin and thick laths respectively correspond to $15 \mathrm{R}$ and $12 \mathrm{H}$ LPSO structures. (d) A fast Fourier transformation (FFT) pattern of the image in (c), showing no diffusive streaks along the stacking direction.

Fig. 2 (a) A low magnification HAADF-STEM image of the right part of (a) obtained alone $[U V .0]_{\alpha}$ zone axis. (b) An atomic resolution HAADF-STEM image of the beginning area in Region 15, showing that $(\mathrm{T} 2)_{3}$ transformed into $\mathrm{T} 1 \overline{\mathrm{T}} 2 \overline{\mathrm{T}} 3$ structure via gliding of Shockley partial dislocations. (c-e) Atomic resolution HAADF-STEM images of $\overline{\mathrm{T}} 8$, T20 and $\overline{\mathrm{T}} 4 \overline{\mathrm{T}} 2$ structures in the midst of $12 \mathrm{H}$ structures in Region 13, 9 and 1, respectively. The line profiles of T8, T20 are also inset in (c) and (d), suggesting these 8 and 20 atomic layers are enriched with $\mathrm{Co} / \mathrm{Y}$ and should be the supersaturated Mg solid solution.

Fig. 3 A histogram illustrates the arrangement of the T2 and (T3T3) structures and the number of layers in various structures in regions 1-16 denoted in Fig.1 (a). This implies that the intimate relationship between perfect structure without planer defects and the (T2) ${ }_{10}$ building blocks.

Fig. 4 Schematic illustration of transformation process of 654R LPSO structures in Mg-Co-Y as-cast alloy.

Table 1 Summary of stacking features of the various structures in Region 1-16. 

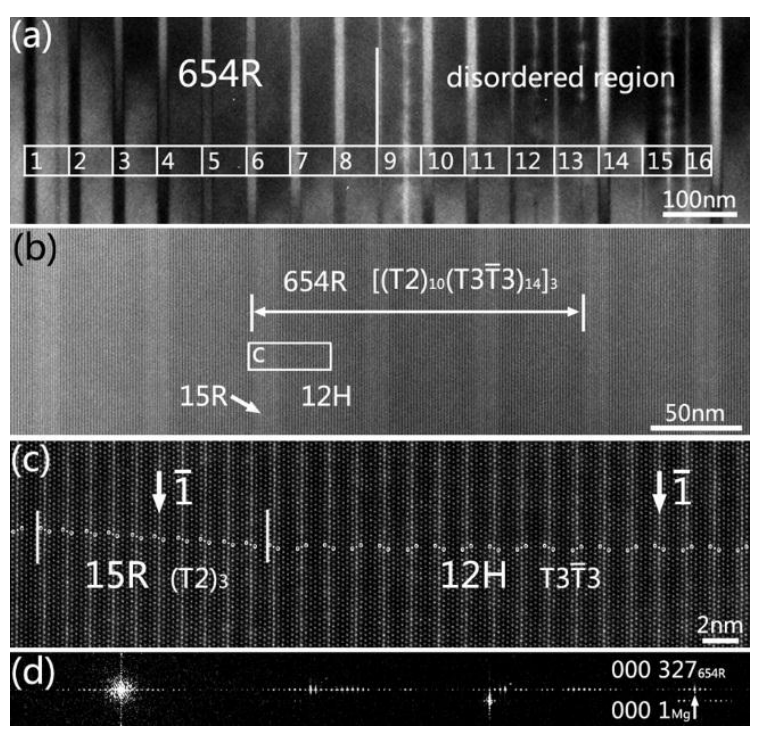


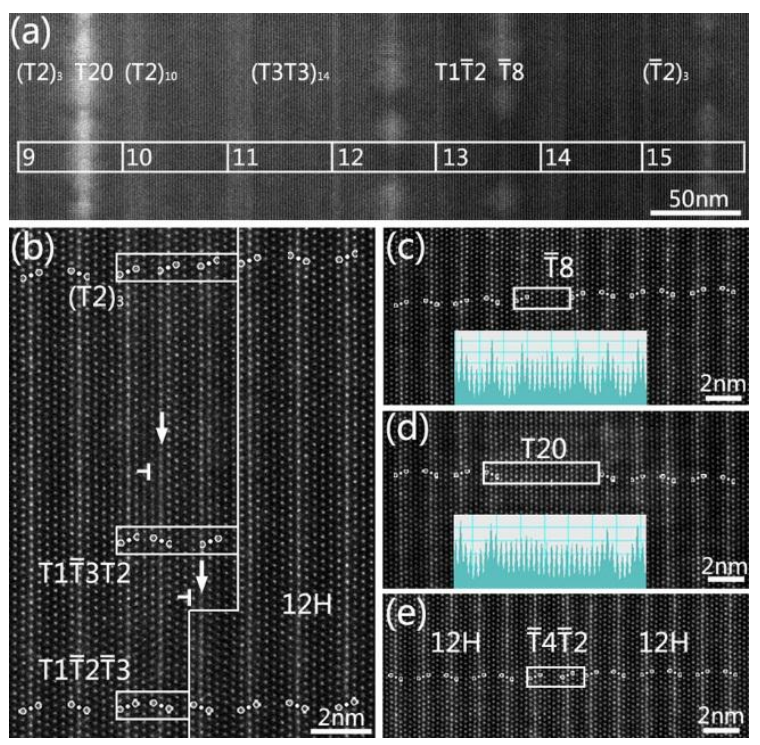




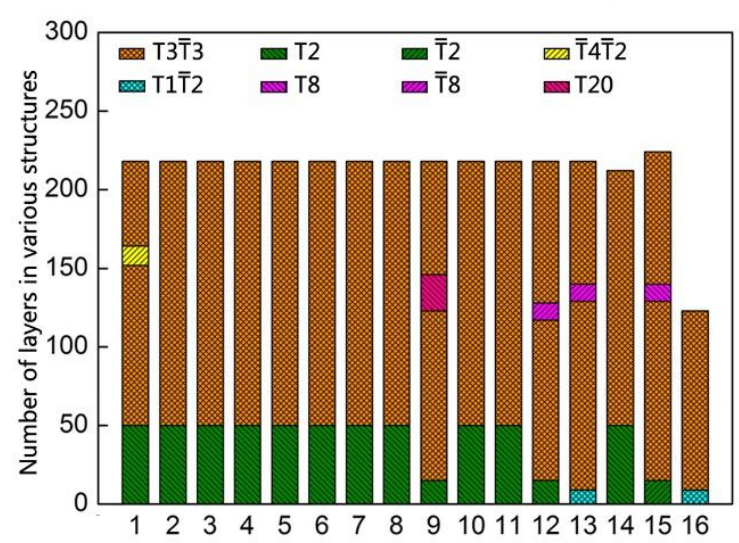


Step 1: formation of supersaturated $\mathrm{Mg}$

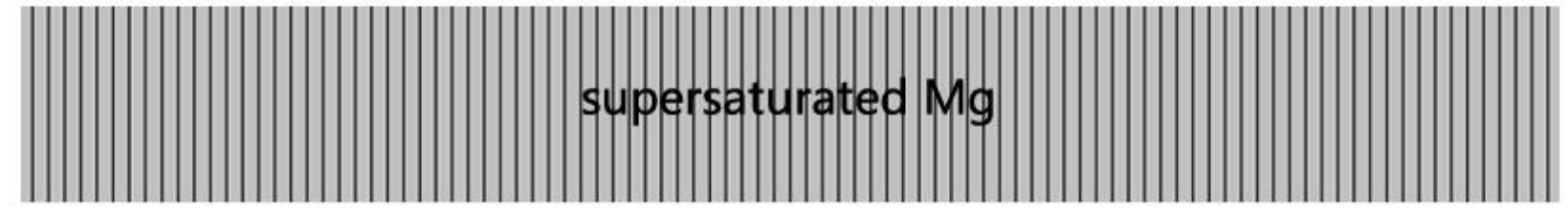

Step 2: nucleation of T2

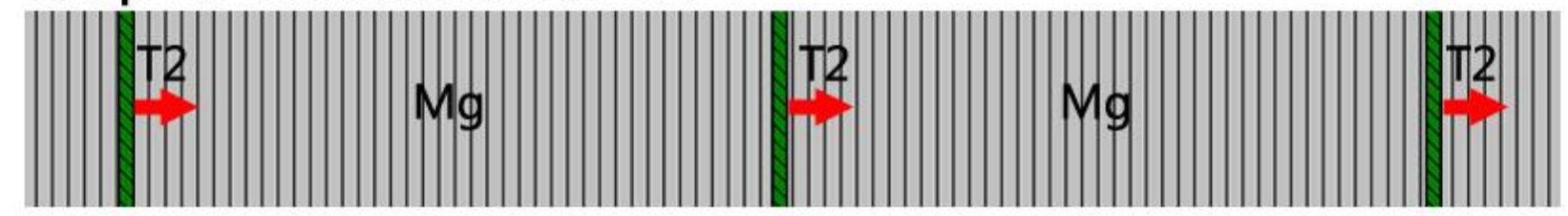

Step 3: growth of T2

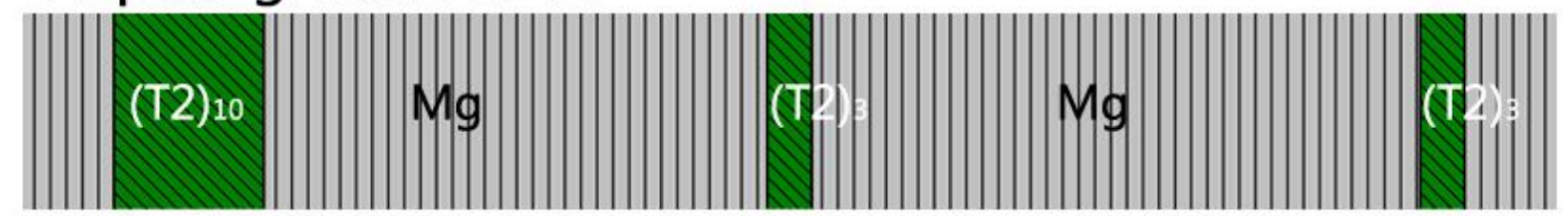

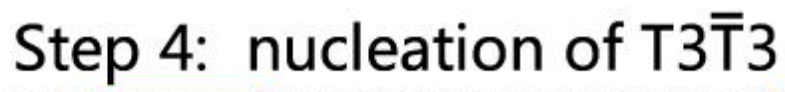

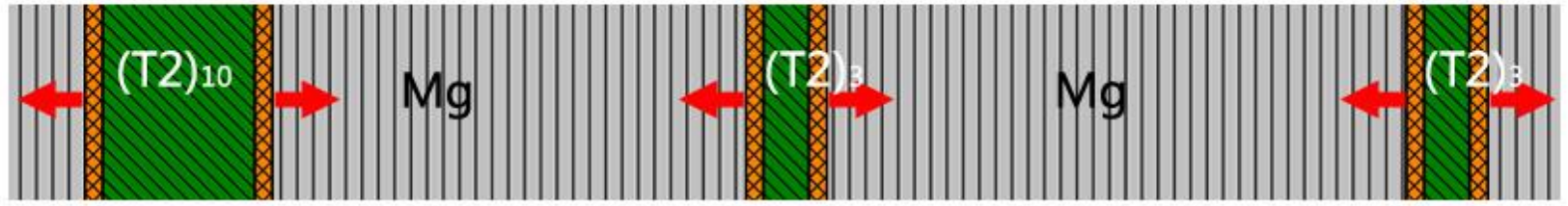

Step 5: growth of T3T3

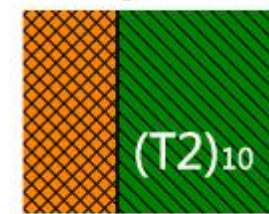

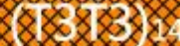

皿 $\mathrm{Mg}$

T3ї3

$\mathrm{T} 2$

血 $\overline{\mathrm{T}} 8$ 


\begin{tabular}{lll}
\hline Regions & Expressions & layers \\
\hline 1 & $(\mathrm{~T} 2)_{10}(\mathrm{~T} 3 \overline{\mathrm{T}} 3)_{8}(\mathrm{~T} 3 \overline{\mathrm{T}} 4 \overline{\mathrm{T}} 2 \overline{\mathrm{T}} 3)(\mathrm{T} 3 \overline{\mathrm{T}} 3)_{4}$ & 218 \\
$2-8$ & $(\mathrm{~T} 2)_{10}(\mathrm{~T} 3 \overline{\mathrm{T}} 3)_{14}$ & 218 \\
9 & $(\mathrm{~T} 2)_{3}(\mathrm{~T} 3 \overline{\mathrm{T}} 3)_{9}(\mathrm{~T} 20)(\mathrm{T} 3 \overline{\mathrm{T}} 3)_{6}$ & 218 \\
$10-11$ & $(\mathrm{~T} 2)_{10}(\mathrm{~T} 3 \overline{\mathrm{T}} 3)_{14}$ & 218 \\
12 & $(\mathrm{~T} 2)_{3}(\mathrm{~T} 3 \overline{\mathrm{T}} 3)_{8}(\mathrm{~T} 3 \overline{\mathrm{T}} 8 \overline{\mathrm{T}} 3)(\mathrm{T} 3 \overline{\mathrm{T}} 3)_{7}$ & 218 \\
13 & $(\mathrm{~T} 1 \overline{\mathrm{T}} 2 \overline{\mathrm{T}} 3)(\mathrm{T} 3 \overline{\mathrm{T}} 3)_{9} \mathrm{~T} 3 \overline{\mathrm{T}} 8 \overline{\mathrm{T}} 3(\mathrm{~T} 3 \overline{\mathrm{T}} 3)_{6}$ & 218 \\
14 & $(\mathrm{~T} 2)_{10}(\mathrm{~T} 3 \overline{\mathrm{T}} 3)_{13} \mathrm{~T} 3$ & 212 \\
15 & $(\overline{\mathrm{T}} 2)_{3}(\overline{\mathrm{T}} 3 \mathrm{~T} 3)_{9} \overline{\mathrm{T}} 3(\mathrm{~T} 8)(\mathrm{T} 3 \overline{\mathrm{T}} 3)_{7}$ & 224 \\
16 & $(\mathrm{~T} 1 \overline{\mathrm{T}} 2 \overline{\mathrm{T}} 3)(\overline{\mathrm{T}} 3 \mathrm{~T} 3)_{9}$ & 123 \\
\hline
\end{tabular}



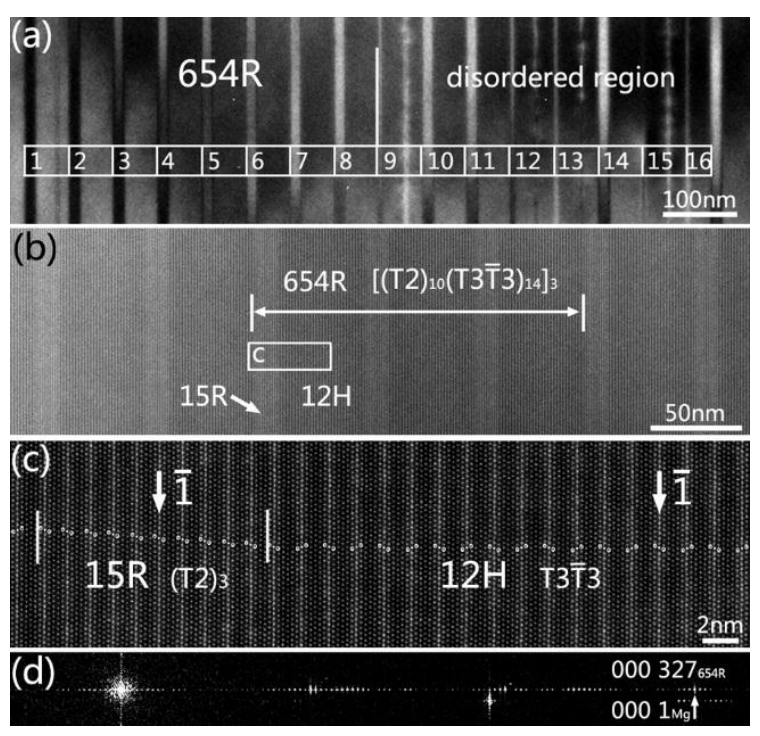